\title{
Article \\ Comparative In Vitro Evaluation of the Primary Stability in D3 Synthetic Bone of Two Different Shapes and Pitches of the Implant Threads
}

\author{
Stefano Fanali ${ }^{1,+}$, Margherita Tumedei ${ }^{1, *,+} \mathbb{D}$, Pamela Pignatelli ${ }^{1}$ (D) Alessandra Lucchese ${ }^{2,3,4}$ (D), \\ Francesco Inchingolo ${ }^{5}$, Adriano Piattelli ${ }^{1,6,7,8}$ and Giovanna Iezzi ${ }^{1}$
}

check for

updates

Citation: Fanali, S.; Tumedei, M.

Pignatelli, P.; Lucchese, A.;

Inchingolo, F.; Piattelli, A.; Iezzi, G.

Comparative In Vitro Evaluation of the Primary Stability in D3 Synthetic Bone of Two Different Shapes and Pitches of the Implant Threads. Appl. Sci. 2021, 11, 5612. https://doi.org/ 10.3390/app11125612

Academic Editor: Giuseppe Perale

Received: 1 June 2021

Accepted: 15 June 2021

Published: 17 June 2021

Publisher's Note: MDPI stays neutral with regard to jurisdictional claims in published maps and institutional affiliations.

Copyright: (c) 2021 by the authors Licensee MDPI, Basel, Switzerland. This article is an open access article distributed under the terms and conditions of the Creative Commons Attribution (CC BY) license (https:/ / creativecommons.org/licenses/by/ $4.0 /)$.
1 Department of Medical, Oral and Biotechnological Sciences, University "G. D'Annunzio" of Chieti-Pescara, Via dei Vestini 31, 66100 Chieti, Italy; s.fanali@unich.it (S.F.); pamelapignatelli89p@gmail.com (P.P.); apiattelli@unich.it (A.P.); gio.iezzi@unich.it (G.I.)

2 Unit of Orthodontics, Division of Dentistry IRCCS San Raffaele Scientific Institute, 20132 Milan, Italy; lucchese.alessandra@hsr.it

3 Unit of Orthodontics, School of Dentistry, Vita-Salute San Raffaele University, 20132 Milan, Italy

4 Unit of Dentistry, Research Center for Oral Pathology and Implantology, IRCCS San Raffaele Scientific Institute, 20132 Milan, Italy

5 Department of Interdisciplinary Medicine, University of Bari “Aldo Moro”, 70121 Bari, Italy; francesco.inchingolo@uniba.it

6 Biomaterials Engineering, Catholic University of San Antonio de Murcia (UCAM), Av. de los Jerónimos, 135, 30107 Guadalupe, Spain

7 Fondazione Villaserena per la Ricerca, Via Leonardo Petruzzi 42, 65013 Città Sant'Angelo, Italy

8 Casa di Cura Villa Serena del Dott. L. Petruzzi, Via Leonardo Petruzzi 42, 65013 Città Sant'Angelo, Italy

* Correspondence: margytumedei@yahoo.it

+ These two Authors had an equal contribution to the study. SF for the execution of the experimental portion, MT for data collection, data analysis, statistical evaluation, final editing of the manuscript.

Abstract: Background: Implant primary stability can be affected by several factors related to implant macrogeometry, local anatomy, and surgical techniques. The aim of this research was to study primary stability on polyurethane foam sheets of wide-threaded implant design compared to narrowthreaded implants. Materials and methods: Two different implant designs were positioned on D3 density polyurethane blocks in a standardized environment: the wide-threaded implant and the narrow-threaded implant, for a total of 160 specimens. Moreover, for each group, two different sizes were considered: $3.8 \mathrm{~mm} \times 12 \mathrm{~mm}$ and $4.8 \mathrm{~mm} \times 12 \mathrm{~mm}$. The insertion torque (IT) values, the removal strength (RT), and the Periotest analyses were evaluated. Results: A significantly higher IT and RT was reported for wide-threaded implants and two-stage implants $(p<0.01)$, compared to the narrow-threaded implants. The diameters seemed to provide a significant effect on the primary stability for both implants' geometry $(p<0.01)$. A higher mean of the one-stage implant was evident in the Periotest measurements $(p<0.01)$. Conclusions: Both of the implants showed sufficient stability in polyurethane artificial simulation, while the wide-threaded implant design showed a higher primary stability on alveolar cancellous synthetic bone in vitro. Additionally, the prosthetic joint connection seemed to have a determinant effect on Periotest analysis, and the one-stage implants seemed to provide a high stability of the fixture when positioned in the osteotomy, which could be important for the immediate loading protocol.

Keywords: polyurethane; artificial bone; dental implant; primary stability; submerged implants

\section{Introduction}

Implant-supported rehabilitation represents a predictable and long-term successful treatment option for fixed prosthetic rehabilitation of the edentulous arches [1,2]. Obtaining primary stability is the main goal for the successful healing of dental implants and osseointegration processes, which are deeply influenced by several factors related to the device 
characteristics such as the geometry of the fixture and surface characteristics [3-8]. Moreover, these important aspects are related to surgical technique and the quality/quantity of the receiving bone volumes, and are determinant for achieving osseointegration of dental implants in the maxillary bones [9-11].

In the literature, the use of retentive microgeometry and surface treatments have been proposed in order to increase the primary stability and osseointegration levels of dental implants $[3,12,13]$. Anatomically, the micromechanical stability of the interface is closely related to the frictional interaction generated during the implant positioning in the osteotomy site [14-16]. Histologically, this relationship is associated with an increase in Bone-Implant Contact (BIC) when it is correlated in vivo with higher primary stability, which significantly influences the maturation and mineralization process of peri-implant bone, inducing secondary stability $[14,17]$. Different methods have been proposed to evaluate the stability parameters of dental implants, including insertion torque (IT), removal value (RT), and implant micromotion using the Periotest score $[3,17,18]$.

The Periotest represents a repeatable method that can be applied both to dental elements and to natural teeth, achieving a digital evaluation of the micromovement in a standardized and calibrated form. The IT and RT differs from the previous method according to a nonrepeatable evaluation model, determined by the mechanical interaction generated instantly between the fixture and the bone walls of the implant during the implant positioning phase [19]. In the literature, the geometry of the threads, surface characteristics, and implant microstructures can significantly affect IT and RT values [3], especially in sites characterized by a lack of bioavailability of peri-implant bone and postextractive socket. The use of polyurethane solid sheets as artificial bone has been shown by the American Society for Testing and Materials International (ASTM) to be able to perform the biomechanical tests for implant fixtures in a standardized laboratory environment; however, it excludes the local and structural variables typical of natural bone tissue [20].

Solid rigid polyurethane is characterized by physical and mechanical properties, including compression, elasticity, and a homogeneous structure similar to bone, in order to simulate the different densities of the different maxillary and mandibular regions [20-27].

The aim of this study is to evaluate the primary stability obtained using polyurethane in a block of two different implant designs, consisting of different microgeometry, shape, and pitch of the implant threads.

\section{Materials and Methods}

In the present in vitro study, a total of 160 implants, 40 screws for each study group, were tested for homogeneous density using polyurethane foam blocks that were 12.5 pound per cubic foot (PCF) (SawBones H, Pacific Research Laboratories Inc, Vashon, Washington, USA), following the manufacturer osteotomy drilling protocol (F.M.D., Rome Italy) (Figure 1).

- Group A: cylindrical one-stage wide thread pitch implant, $3.8 \mathrm{~mm}$ diameter $\times 12 \mathrm{~mm}$ length (Crystal, F.M.D., Rome Italy);

- Group B: cylindrical one-stage wide thread pitch implant, $4.8 \mathrm{~mm}$ diameter $\times 12 \mathrm{~mm}$ length (Crystal, F.M.D., Roma Italy);

- Group C: cylindrical two-stage narrow thread pitch, $3.8 \mathrm{~mm}$ diameter $\times 12 \mathrm{~mm}$ length (Elisir, FMD, Rome Italy);

- Group D: cylindrical two-stage narrow thread pitch, $4.8 \mathrm{~mm}$ diameter $\times 12 \mathrm{~mm}$ length (Elisir, FMD, Rome Italy).

The drilling protocol for the polyurethane in the block of 12.5 PCF implants for the 3.8 diameter implants was: pilot drill; $2.3 \mathrm{~mm}$ cylindrical drill; $2.5 \mathrm{~mm}$ cylindrical drill; $2.8 \mathrm{~mm}$ cylindrical drill; $3.2 \mathrm{~mm}$ cylindrical drill; and $3.7 \mathrm{~mm}$ cylindrical drill cutter, at a speed of $800 \mathrm{rpm}$ in a clockwise rotation (Figure 2).

The sequence of the drilling protocol on polyurethane in the in block of 12.5 PCF implants for the 4.8 diameter implants was: pilot drill; $2.3 \mathrm{~mm}$ cylindrical drill; $2.5 \mathrm{~mm}$ cylindrical drill; $2.8 \mathrm{~mm}$ cylindrical drill; $3.2 \mathrm{~mm}$ cylindrical drill; $3.7 \mathrm{~mm}$ cylindrical drill; 
and $4.2 \mathrm{~mm}$ drill, at a speed of $800 \mathrm{rpm}$ in a clockwise rotation, and a final passage with a tap (Figure 2, Figure 3A,B).

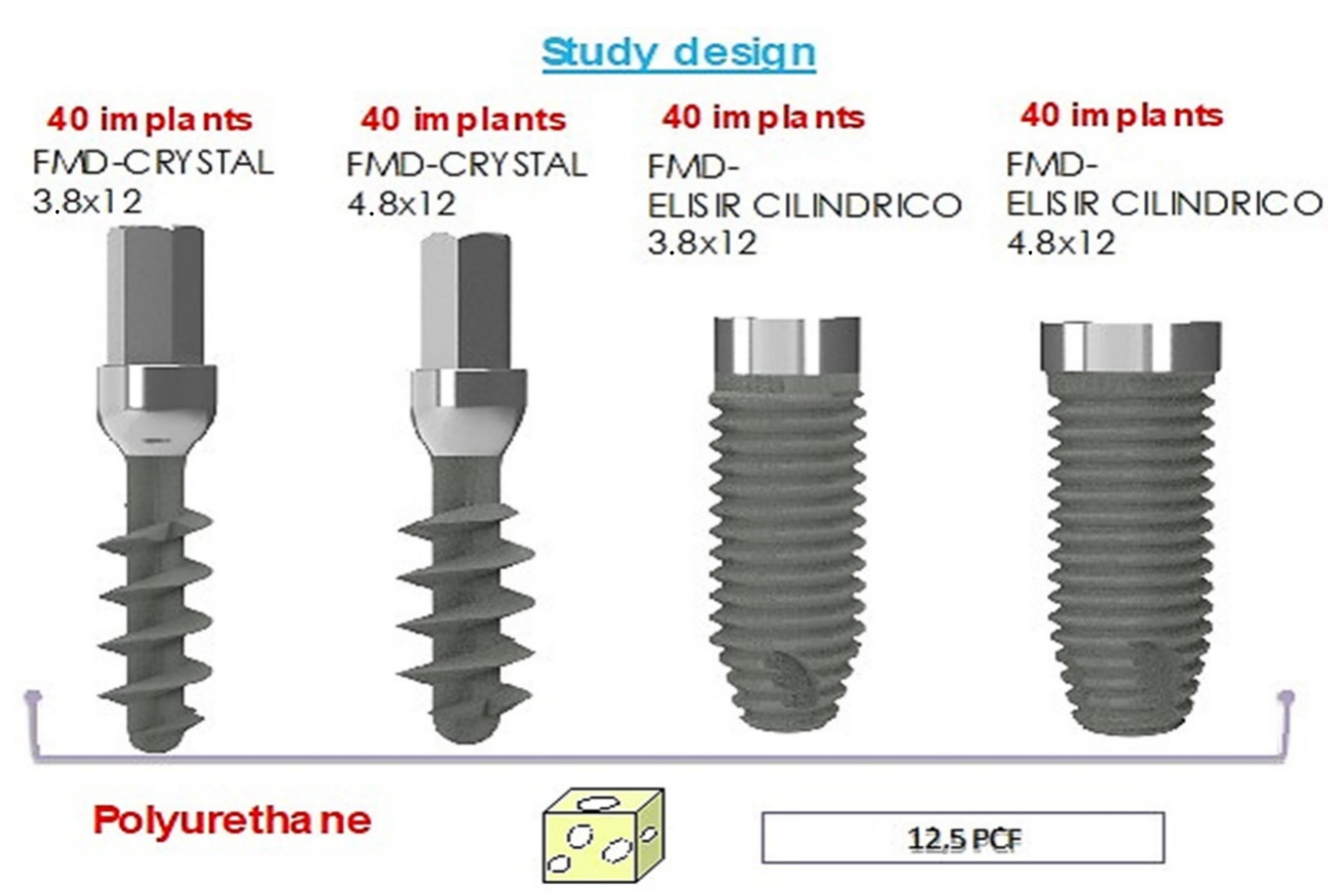

Figure 1. Graphic summary of the study design.
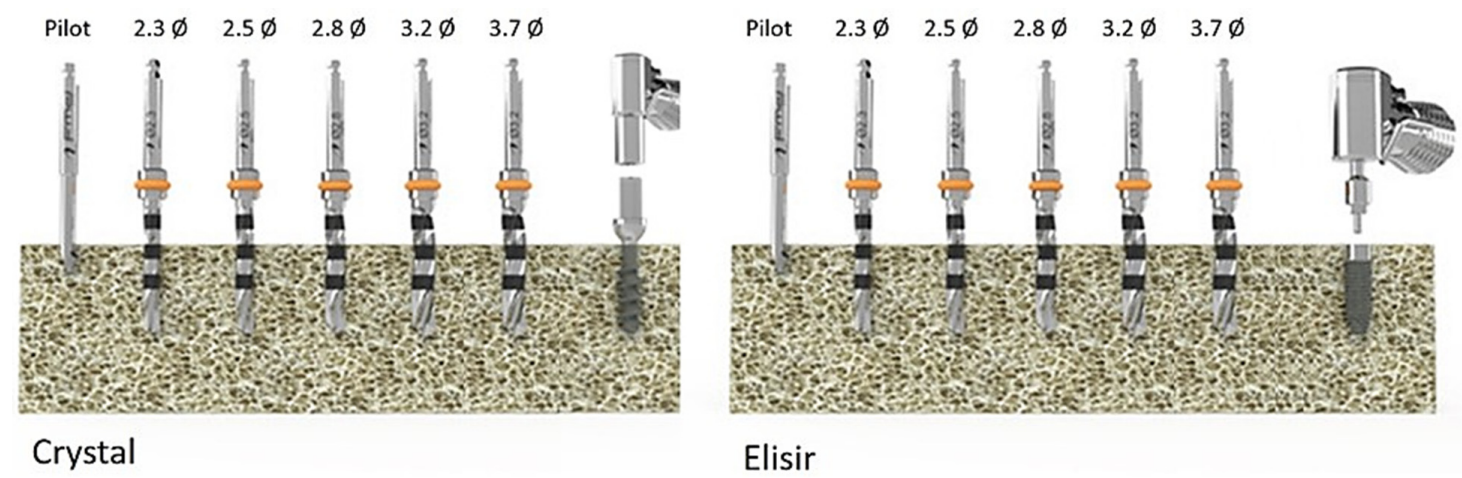

Elisir

Figure 2. Drilling sequence protocol for the Elisir and Crystal Implant $3.8 \mathrm{~mm} \varnothing$ positioning. For both $4.8 \mathrm{~mm} \varnothing \mathrm{implants,}$ one more drill with a $4.2 \mathrm{~mm}$ drill was performed.

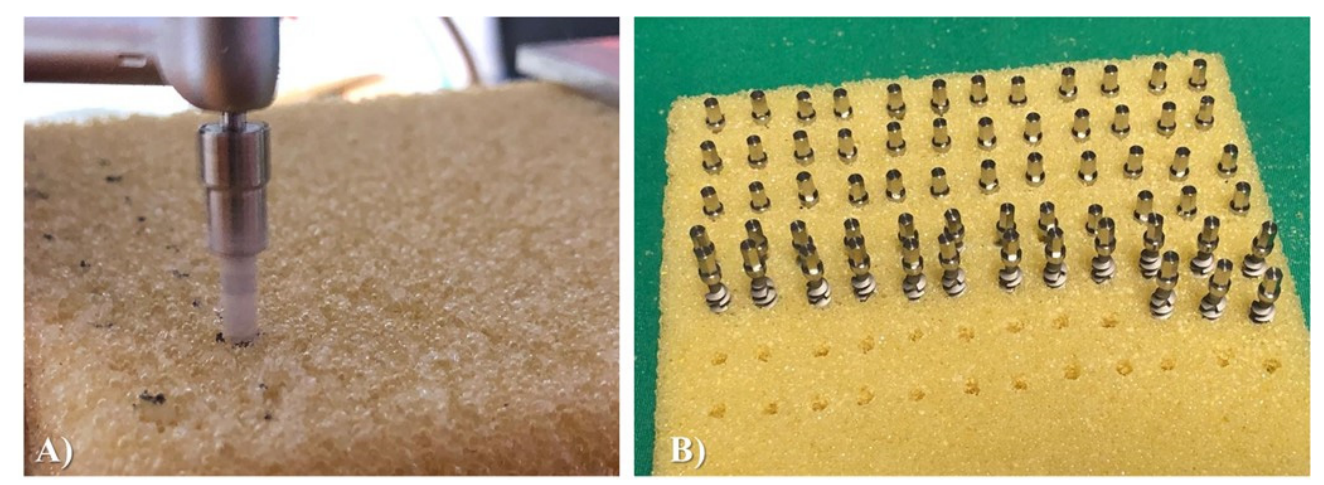

Figure 3. Experimental procedure of the investigation: (A) Polyurethane block drilling for implant positioning; (B) Dental implant positioned into the synthetic block. 


\subsection{Periotest Measurement}

The implant stability was evaluated by Periotest (Medizintechnik, Germany) with an electromechanical punch that strikes the implant a total of 16 times. The tip presents a pressure-sensitive head that records the contact time with the measured object.

The individual noncompliant pulses are eliminated. The Periotest Scale is closely related to dental mobility through a scale of values which are as follows:

1. From -8 to 0: good bone integration; the implant is well integrated and can be loaded.

2. From +1 to +9 : clinical control is required; the implant load is mostly not possible yet.

3. From +10 to +50 : bone integration is not enough; the system cannot be loaded.

The measurements were performed two times by a single operator and the average values were considered for the statistical evaluation and intra-examiner agreement assessment.

\subsection{Insertion Torque and Removal Measurements}

The experimental implants were positioned to record the IT, while the tensile and removal resistance was recorded by dynamometric analysis during removal of the implant from the block.

IT was evaluated using the OMEGA digital dynamometer (Arthur-Sauvé, St-Eustache, $\mathrm{QB}$, Canada) coupled with the implant insertion driver as per the implant system protocol.

\subsection{Statistical Analysis}

The sample size measurement was oriented in accordance with the mean and standard deviation of a previous study, [28] while the alpha error was set at 0.05 with an effect size of 0.34 , and the power (1-beta) was 0.95 . The minimum number was 39 sites for each drilling protocol, with a total of 156 sites.

Descriptive statistics are provided in summary tables by group based on the type of measurement of the summarized result. The general descriptive statistics for continuous outcome measures included: number of observed values, mean with a $95 \% \mathrm{CI}$, standard deviation, median, minimum and maximum values. The hypothesis was tested with an analysis of variance (ANOVA) with basal values of IT, RT, and Periotest. The accuracy of the Periotest measurement was evaluated by Bland-Altman and linear regression models to determine the agreement between the ISQ measurements. The groups were compared at the $5 \%$ significance level. Data collection and statistical analysis were performed using StatPlus 6 software (AnalystSoft Inc., Walnut, CA, USA).

\section{Results}

\subsection{Insertion and Removal Torque}

The IT and RT means of the study groups were presented in Tables 1-3. The group D implant showed a significantly higher IT mean of $20.75 \pm 3.5 \mathrm{Ncm}$ compared to group A $(16.83 \pm 1.9 \mathrm{Ncm})$, group B $(19.1 \pm 1.2 \mathrm{Ncm})$ and group C $(12.65 \pm 3.0 \mathrm{Ncm})$. The group $\mathrm{D}$ implant showed a significantly higher RT mean of $15.85 \pm 3.2 \mathrm{Ncm}$ compared to group A $(5.85 \pm 1.09 \mathrm{Ncm})$, group B $(8.45 \pm 1.28 \mathrm{Ncm})$ and group C $(10.2 \pm 3.2 \mathrm{Ncm})$.

An IT and RT significant difference was reported between the study groups as being in favour of the wide diameter implant design (Group B-D), compared to the narrow diameter implant (Groups A-C) (Figure 4A,B) (Tables 2 and 4$)(p<0.01)$.

Table 1. Summary of Insertion Torque for the study groups.

\begin{tabular}{ccc}
\hline Insertion Torque $[\mathbf{N} / \mathbf{c m}]$ & Mean & SD \\
\hline CRYSTAL 3.8 & 16.83 & 1.947 \\
\hline CRYSTAL 4.8 & 19.1 & 1.236 \\
\hline ELISIR 3.8 & 12.65 & 3.034 \\
\hline ELISIR 4.8 & 20.75 & 3.514 \\
\hline
\end{tabular}


Table 2. ANOVA post-hoc of insertion torque comparisons of the study groups.

\begin{tabular}{cccc}
\hline Insertion Torque & Mean Diff. & $\mathbf{9 5 . 0 0 \%}$ CI of Diff. & Adjusted $\boldsymbol{p}$ Value \\
\hline CRYSTAL 3.8 vs. CRYSTAL 4.8 & -2.275 & -3.819 to -0.7306 & 0.0008 \\
\hline CRYSTAL 3.8 vs. ELISIR 3.8 & 4.175 & 2.631 to 5.719 & $<0.0001$ \\
\hline CRYSTAL 3.8 vs. ELISIR 4.8 & -3.925 & -5.469 to -2.381 & $<0.0001$ \\
\hline CRYSTAL 4.8 vs. ELISIR 3.8 & 6.450 & 4.906 to 7.994 & $<0.0001$ \\
\hline CRYSTAL 4.8 vs. ELISIR 4.8 & -1.650 & -3.194 to -0.1056 & 0.0297 \\
\hline
\end{tabular}

Table 3. Summary of removal torque means of the study groups.

\begin{tabular}{ccc}
\hline Removal [N/cm] & Mean & SD \\
\hline CRYSTAL 3.8 & 5.85 & 1.099 \\
\hline CRYSTAL 4.8 & 8.45 & 1.28 \\
\hline ELISIR 3.8 & 10.2 & 3.057 \\
\hline ELISIR 4.8 & 15.85 & 3.215 \\
\hline
\end{tabular}

Table 4. ANOVA post-hoc of removal mean comparisons of the study groups.

\begin{tabular}{cccc}
\hline Removal & Mean Diff. & $\mathbf{9 5 . 0 0 \%}$ CI of Diff. & Adjusted $\boldsymbol{p}$ Value \\
\hline CRYSTAL 3.8 vs. CRYSTAL 4.8 & -2.600 & -4.014 to -1.186 & $<0.0001$ \\
\hline CRYSTAL 3.8 vs. ELISIR 3.8 & -4.350 & -5.764 to -2.936 & $<0.0001$ \\
\hline CRYSTAL 3.8 vs. ELISIR 4.8 & -10.00 & -11.41 to -8.586 & $<0.0001$ \\
\hline CRYSTAL 4.8 vs. ELISIR 3.8 & -1.750 & -3.164 to -0.3359 & 0.0072 \\
\hline CRYSTAL 4.8 vs. ELISIR 4.8 & -7.400 & -8.814 to -5.986 & $<0.0001$ \\
\hline
\end{tabular}

INSERTION TORQUE

A)

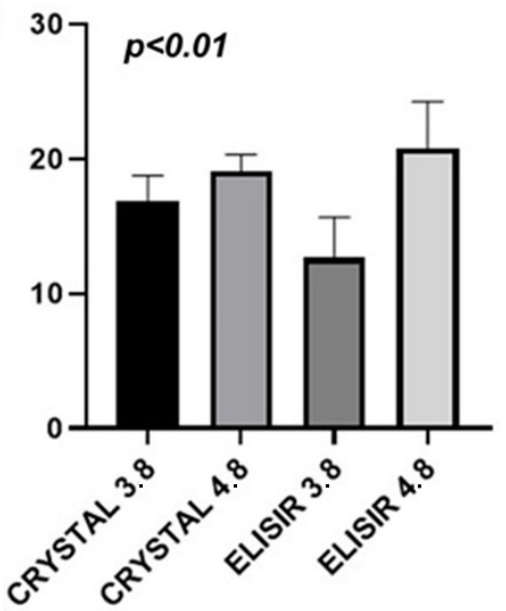

REMOVAL TORQUE

B)

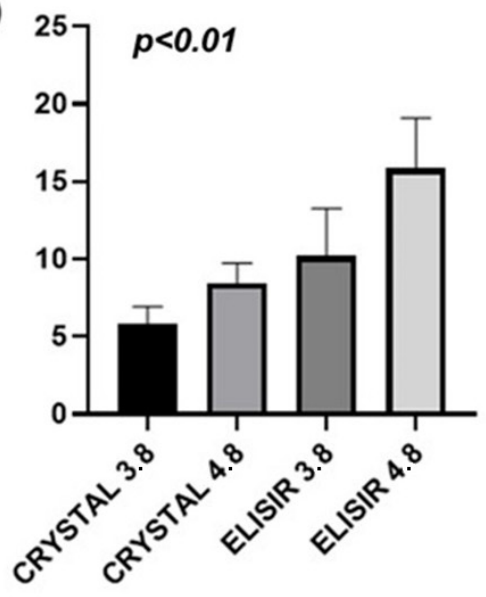

PERIOTEST

C)

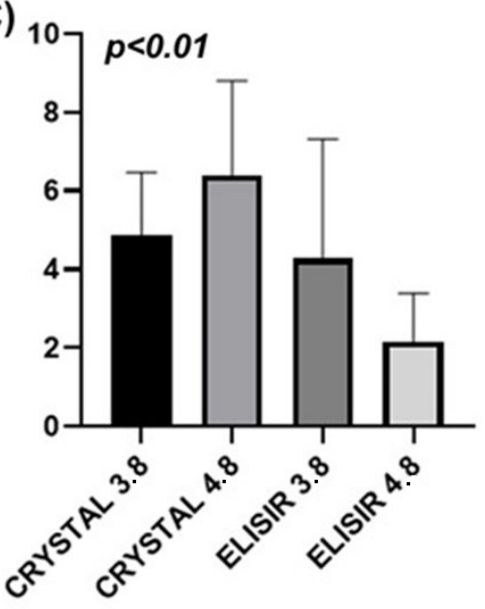

Figure 4. Insertion torque (A), removal (B) and Periotest analysis (C) study outcome. Means and standard deviations are presented in tables $(p<0.05)$.

The study group comparison showed a significant increase in IT and RT related to the dental implant diameter when compared to smaller screws (Tables 2 and 4).

All implant fixtures showed no evidence of loss of stability during positioning in the preparation site. 


\subsection{Periotest Stability Measurement}

The intra-examiner agreement of the Periotest assessment was presented in Figure 5, showing a mean bias of $0.17 \pm 0.5$ ( $95 \% \mathrm{CI}$ : -2.914 to 3.258$)$.

\section{BLAND ALTMAN PLOT Periotest}

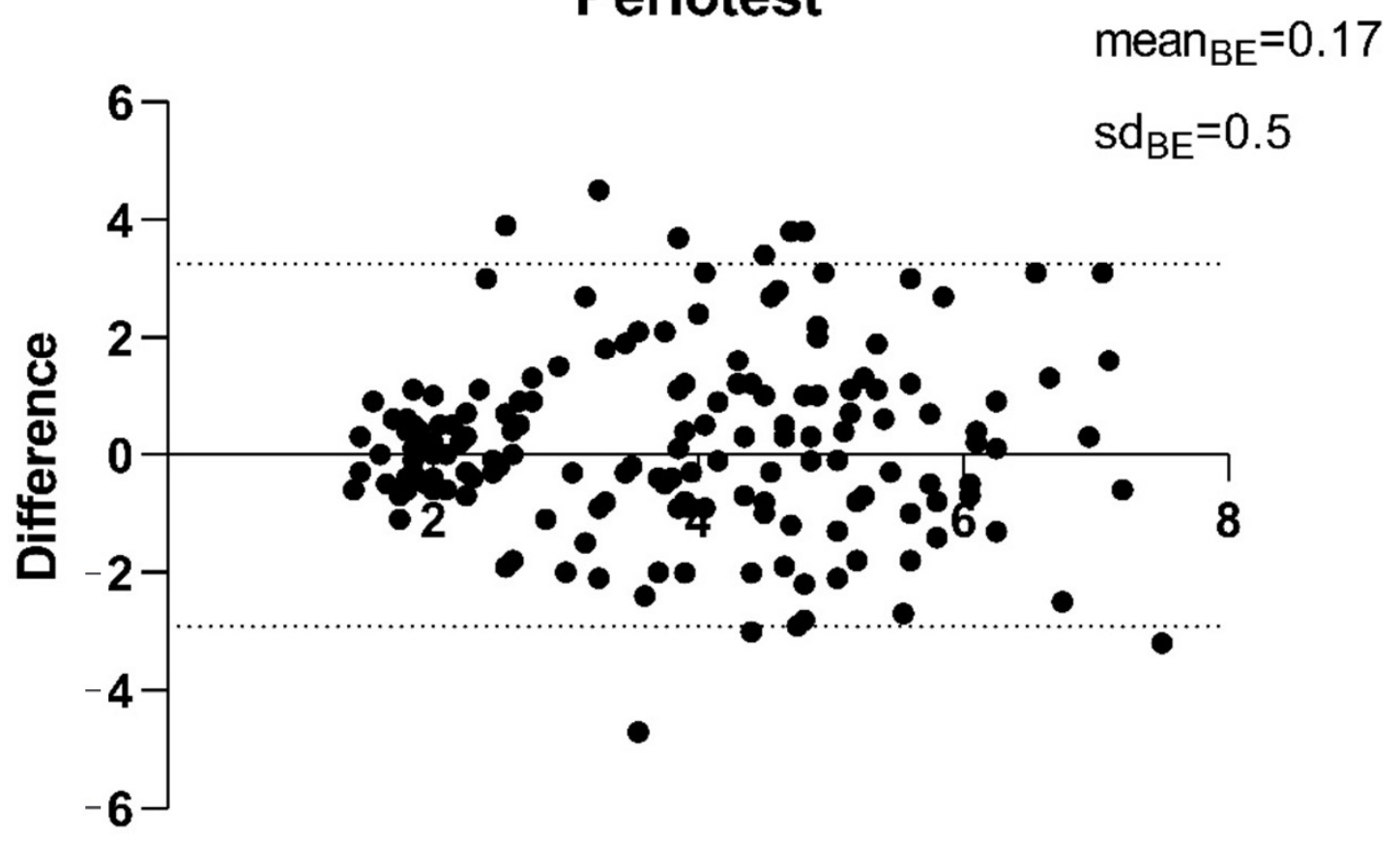

Figure 5. Detail of the Bland-Altman plot of the Periotest assessment.

The Periotest measurement showed lower stability of narrow thread implants (B-D), compared to the wide diameter design $(A-C)(p<0.01)$ (Figure 4 C, Table 5). The increasing diameter produced significantly higher implant stability levels in both screw types $(p<0.01)$ (Table 6).

Table 5. Summary of the Periotest means for the study groups.

\begin{tabular}{ccc}
\hline Periotest & Mean & SD \\
\hline CRYSTAL 3.8 & 4.3 & 1.1 \\
\hline CRYSTAL 4.8 & 5.1 & 1.4 \\
\hline ELISIR 3.8 & 4.1 & 1.6 \\
\hline ELISIR 4.8 & 2.0 & 0.4 \\
\hline
\end{tabular}

Table 6. ANOVA post-hoc of Periotest comparisons for the study groups.

\begin{tabular}{cccc}
\hline Periotest & Mean Diff. & $\mathbf{9 5 . 0 0 \%}$ CI of Diff. & Adjusted $\boldsymbol{p}$ Value \\
\hline CRYSTAL 3.8 vs. CRYSTAL 4.8 & -1.534 & -2.771 to -0.2966 & 0.0085 \\
\hline CRYSTAL 3.8 vs. ELISIR 3.8 & 0.5813 & -0.6559 to 1.818 & 0.6632 \\
\hline CRYSTAL 3.8 vs. ELISIR 4.8 & 4.239 & 3.002 to 5.476 & $<0.0001$ \\
\hline CRYSTAL 4.8 vs. ELISIR 3.8 & 2.124 & 0.8866 to 3.361 & 0.0001 \\
\hline CRYSTAL 4.8 vs. ELISIR 4.8 & -1.534 & -2.771 to -0.2966 & 0.0085 \\
\hline
\end{tabular}


Moreover, an increased micromovement was detected for the two-stage implants of group $C$ and group D, compared to the lower means of the monolithic implants of group A and group $\mathrm{B}(p<0.01)$.

\section{Discussion}

The vital bone represents a dynamic tissue in constant physiological remodelling as a consequence of the external stimuli and function [29-32]. As a consequence of the loss of function, the edentulism often determines not only a decrease in ridge volume, but also a decrement of bone quality and density [33-36].

A greater component of alveolar cancellous bone, instead of poor cortical bone, is clinically associated with increased difficulty to obtain sufficient implant stability and osseointegration [37]. This research investigation has been focusing on the mechanical features of dental implants positioned into synthetic polyurethane blocks within a standardized and calibrated environment. The outcome of the present investigation showed a strict relationship between bone density and the primary stability of implants that is significantly related to the geometry and the shapes of the screw. In fact, the wide-threaded cylindrical implants placed according to the standard drilling protocol showed a significantly higher primary stability, insertion torque, and removal strength. In contrast, the Periotest measurement showed an inverse relationship within the group that could be influenced by the prosthetic joint $[35,36,38,39]$. It is well known that the transfer of the occlusal forces can play a key role for the successful maintenance of the soft and hard peri-implant tissues [40-42]. These aspects could be determinant in the case of the immediate loading of the dental implant, while the occlusal stresses occur in contact of a nonmature osteoid bone interfaces $[24,25,43]$. On the contrary, a two-stage technique takes advantage of a submerged healing period during which the implant fixture completes the osseointegration process and is protected by the oral biofilm and pathogen action $[44,45]$.

In the present study, both of the dental implant macrogeometries showed a stability parameter optimal for an occlusal loading in the simulated D3 bone density. This condition is clinically associated with a proper ratio between the cortical and cancellous bone, where the first one is the determinant factor for the immediate stability of the implant, while the trabecular bone is able to provide the nutritional and vascular support necessary for the secondary stability, after the healing period [46].

These suggest a confirmation of Frost's mechanostatic theory while the loading protocol is able to generate two different biological responses of the bone tissues $[47,48]$. The modeling is a process that produces an adaptation of the bone to the overloads, producing a new bone formation and a morphological change of the anatomy architecture. The remodeling process induces a response to the underloads with bone resorption next to the marrow, maintaining the functional bone [47-50]. These adaptation models are strongly influenced by prosthetic, metabolic, and anatomic factors, and the local bone density, while an adapted state should be maintained between 1000-1500 microstrain for immediate, early, delayed, and late loading protocols $[47,48]$.

The limit of the present investigation was that the simulation did not provide a long term evaluation of implant stability without the characteristics of the environment of the intraoral cavity and saliva. Moreover, the study did not consider the interindividual characteristics and a biological response of human bone to the implant treatment.

In literature, lower primary stability of dental implants is related to a decreased level of osseointegration and bone-to-implant contact in retrieved implants [51-57]. In a split mouth study, Amari et al. reported that higher implant osseointegration was observed at $30 \mathrm{Ncm}$ insertion torque compared to a $<10 \mathrm{Ncm}$ torque group at 8 weeks [58].

The authors concluded that with lower osseointegration, observed in low-torque implants and in the case of poor bone quality, an under preparation of the recipient sites should be applied, and longer and wider implants should be positioned [58-66]. 


\section{Conclusions}

In conclusion, the implant macrodesign and thread shape significantly influences the frictional capability, and ultimately the primary stability in low density polyurethane blocks. From a clinical point of view, the effects of different macrodesign characteristics should be carefully interpreted and considered to improve the implant stability and osseointegration quality into alveolar cancellous bone in vivo.

Author Contributions: Conceptualization, A.P., S.F., G.I.; methodology, S.F., M.T., A.P., G.I.; software, M.T., A.P.; validation, A.P., S.F., G.I., F.I.; formal analysis, A.P., S.F., G.I., F.I.; investigation, A.P., S.F., G.I., F.I., P.P.; resources, S.F., A.P.; data curation, A.L., M.T., P.P.; writing-original draft preparation, M.T., A.P.; writing-review and editing, A.P., A.L., M.T. All authors have read and agreed to the published version of the manuscript.

Funding: This research received no external funding.

Institutional Review Board Statement: Not applicable.

Informed Consent Statement: Not applicable.

Data Availability Statement: All experimental data to support the findings of this study are available contacting the corresponding author upon request.

Conflicts of Interest: The authors declare no conflict of interest.

\section{References}

1. $\quad$ Albrektsson, T.; Sennerby, L. State of the Art in Oral Implants. J. Clin. Periodontol. 1991, 18, 474-481. [CrossRef]

2. Iezzi, G.; Degidi, M.; Scarano, A.; Perrotti, V.; Piattelli, A. Bone Response to Submerged, Unloaded Implants Inserted in Poor Bone Sites: A Histological and Histomorphometrical Study of 8 Titanium Implants Retrieved from Man. J. Oral Implantol. 2005, 31, 225-233. [CrossRef]

3. Falco, A.; Berardini, M.; Trisi, P. Correlation between Implant Geometry, Implant Surface, Insertion Torque, and Primary Stability: In Vitro Biomechanical Analysis. Int. J. Oral Maxillofac. Implants 2018, 33, 824-830. [CrossRef] [PubMed]

4. Scarano, A.; Lorusso, F.; Arcangelo, M.; D'Arcangelo, C.; Celletti, R.; de Oliveira, P.S. Lateral Sinus Floor Elevation Performed with Trapezoidal and Modified Triangular Flap Designs: A Randomized Pilot Study of Post-Operative Pain Using Thermal Infrared Imaging. Int. J. Environ. Res. Public Health 2018, 15, 1277. [CrossRef] [PubMed]

5. Scarano, A.; Lorusso, F.; Staiti, G.; Sinjari, B.; Tampieri, A.; Mortellaro, C. Sinus Augmentation with Biomimetic Nanostructured Matrix: Tomographic, Radiological, Histological and Histomorphometrical Results after 6 Months in Humans. Front. Physiol. 2017, 8, 565. [CrossRef]

6. Scarano, A.; Murmura, G.; Vantaggiato, G.; Lauritano, D.; Silvestre-Rangil, J.; DI Cerbo, A.; Lorusso, F. Delayed Expansion of Atrophic Mandible (Deam): A Case Report. ORAL Implantol. 2017, 10, 190-196. [CrossRef]

7. Scarano, A.; Valbonetti, L.; Marchetti, M.; Lorusso, F.; Ceccarelli, M. Soft Tissue Augmentation of the Face with Autologous Platelet-Derived Growth Factors and Tricalcium Phosphate. Microtomography Evaluation of Mice. J. Craniofacial Surg. 2016, 27, 1212-1214. [CrossRef]

8. Scarano, A.; Crincoli, V.; Di Benedetto, A.; Cozzolino, V.; Lorusso, F.; Podaliri Vulpiani, M.; Grano, M.; Kalemaj, Z.; Mori, G.; Grassi, F.R. Bone Regeneration Induced by Bone Porcine Block with Bone Marrow Stromal Stem Cells in a Minipig Model of Mandibular “Critical Size” Defect. Stem Cells Int. 2017, 2017, 9082869. [CrossRef]

9. Degidi, M.; Daprile, G.; Piattelli, A. Influence of Underpreparation on Primary Stability of Implants Inserted in Poor Quality Bone Sites: An in Vitro Study. J. Oral Maxillofac. Surg. 2015, 73, 1084-1088. [CrossRef]

10. Al-Sabbagh, M.; Eldomiaty, W.; Khabbaz, Y. Can Osseointegration Be Achieved without Primary Stability? Dent. Clin. N. Am. 2019, 63, 461-473. [CrossRef]

11. Ahmad, O.K.; Kelly, J.R. Assessment of the Primary Stability of Dental Implants in Artificial Bone Using Resonance Frequency and Percussion Analyses. Int. J. Oral Maxillofac. Implants 2013, 28, 89-95. [CrossRef] [PubMed]

12. Steigenga, J.; Al-Shammari, K.; Misch, C.; Nociti, F.H.; Wang, H.-L. Effects of Implant Thread Geometry on Percentage of Osseointegration and Resistance to Reverse Torque in the Tibia of Rabbits. J. Periodontol. 2004, 75, 1233-1241. [CrossRef] [PubMed]

13. Scarano, A.; Piattelli, A.; Quaranta, A.; Lorusso, F. Bone Response to Two Dental Implants with Different Sandblasted/AcidEtched Implant Surfaces: A Histological and Histomorphometrical Study in Rabbits. BioMed Res. Int. 2017, 2017, 8724951. [CrossRef] [PubMed]

14. Degidi, M.; Perrotti, V.; Piattelli, A.; Iezzi, G. Mineralized Bone-Implant Contact and Implant Stability Quotient in 16 Human Implants Retrieved after Early Healing Periods: A Histologic and Histomorphometric Evaluation. Int. J. Oral Maxillofac. Implants 2010, 25, 45-48. [PubMed] 
15. Tumedei, M.; Savadori, P.; Del Fabbro, M. Synthetic Blocks for Bone Regeneration: A Systematic Review and Meta-Analysis. Int. J. Mol. Sci. 2019, 20, 4221. [CrossRef] [PubMed]

16. Zizzari, V.L.; Berardi, D.; Congedi, F.; Tumedei, M.; Cataldi, A.; Perfetti, G. Morphological Aspect and INOS and Bax Expression Modification in Bone Tissue around Dental Implants Positioned Using Piezoelectric Bone Surgery Versus Conventional Drill Technique. J. Craniofacial Surg. 2015, 26, 741-744. [CrossRef]

17. Coelho, P.G.; Granato, R.; Marin, C.; Bonfante, E.A.; Janal, M.N.; Suzuki, M. Biomechanical and Bone Histomorphologic Evaluation of Four Surfaces on Plateau Root Form Implants: An Experimental Study in Dogs. Oral Surg. Oral Med. Oral Pathol. Oral Radiol. Endod. 2010, 109, e39-e45. [CrossRef]

18. Al-Jetaily, S.; Al-Dosari, A.A. Assessment of Osstell ${ }^{\mathrm{TM}}$ and Periotest ${ }^{\circledR}$ Systems in Measuring Dental Implant Stability (In Vitro Study). Saudi Dent. J. 2011, 23, 17-21. [CrossRef]

19. Gehrke, S.A.; Guirado, J.L.C.; Bettach, R.; Fabbro, M.D.; Martínez, C.P.-A.; Shibli, J.A. Evaluation of the Insertion Torque, Implant Stability Quotient and Drilled Hole Quality for Different Drill Design: An In Vitro Investigation. Clin. Oral Implants Res. 2018, 29, 656-662. [CrossRef]

20. Comuzzi, L.; Iezzi, G.; Piattelli, A.; Tumedei, M. An In Vitro Evaluation, on Polyurethane Foam Sheets, of the Insertion Torque (IT) Values, Pull-Out Torque Values, and Resonance Frequency Analysis (RFA) of NanoShort Dental Implants. Polymers 2019, 11, 1020. [CrossRef]

21. Comuzzi, L.; Tumedei, M.; De Angelis, F.; Lorusso, F.; Piattelli, A.; Iezzi, G. Influence of the dental implant macrogeometry and threads design on primary stability: An in vitro simulation on artificial bone blocks. Comput. Methods Biomech. Biomed. Eng. 2021, 25, 1-9. [CrossRef]

22. Comuzzi, L.; Tumedei, M.; Pontes, A.E.; Piattelli, A.; Iezzi, G. Primary Stability of Dental Implants in Low-Density (10 and 20 Pcf) Polyurethane Foam Blocks: Conical vs. Cylindrical Implants. Int. J. Environ. Res. Public Health 2020, 17, 2617. [CrossRef]

23. Comuzzi, L.; Tumedei, M.; Piattelli, A.; Iezzi, G. Short vs. Standard Length Cone Morse Connection Implants: An In Vitro Pilot Study in Low Density Polyurethane Foam. Symmetry 2019, 11, 1349. [CrossRef]

24. Tumedei, M.; Piattelli, A.; Degidi, M.; Mangano, C.; Iezzi, G. A Narrative Review of the Histological and Histomorphometrical Evaluation of the Peri-Implant Bone in Loaded and Unloaded Dental Implants. A 30-Year Experience (1988-2018). Int. J. Environ. Res. Public Health 2020, 17, 2088. [CrossRef]

25. Tumedei, M.; Piattelli, A.; Degidi, M.; Mangano, C.; Iezzi, G. A 30-Year (1988-2018) Retrospective Microscopical Evaluation of Dental Implants Retrieved for Different Causes: A Narrative Review. Int. J. Periodontics Restor. Dent. 2020, 40, e211-e227. [CrossRef]

26. Fanali, S.; Tumedei, M.; Pignatelli, P.; Inchingolo, F.; Pennacchietti, P.; Pace, G.; Piattelli, A. Implant Primary Stability with an Osteocondensation Drilling Protocol in Different Density Polyurethane Blocks. Comput. Methods Biomech. Biomed. Eng. 2020, 24, 14-20. [CrossRef]

27. Gehrke, S.A.; Tumedei, M.; Aramburú Júnior, J.; Treichel, T.L.E.; Kolerman, R.; Lepore, S.; Piattelli, A.; Iezzi, G. Histological and Histomorphometrical Evaluation of a New Implant Macrogeometry. A Sheep Study. Int. J. Environ. Res. Public Health 2020, 17, 3477. [CrossRef]

28. Comuzzi, L.; Tumedei, M.; Piattelli, A.; Iezzi, G. Osseodensification Drilling vs. Standard Protocol of Implant Site Preparation: An In Vitro Study on Polyurethane Foam Sheets. Prosthesis 2020, 2, 76-86. [CrossRef]

29. Van der Weijden, F.; Dell'Acqua, F.; Slot, D.E. Alveolar Bone Dimensional Changes of Post-Extraction Sockets in Humans: A Systematic Review. J. Clin. Periodontol. 2009, 36, 1048-1058. [CrossRef]

30. Scarano, A.; Lorusso, F.; Ravera, L.; Mortellaro, C.; Piattelli, A. Bone Regeneration in Iliac Crestal Defects: An Experimental Study on Sheep. BioMed Res. Int. 2016, 2016, 4086870. [CrossRef]

31. Scarano, A.; de Oliveira, P.S.; Traini, T.; Lorusso, F. Sinus Membrane Elevation with Heterologous Cortical Lamina: A Randomized Study of a New Surgical Technique for Maxillary Sinus Floor Augmentation without Bone Graft. Materials 2018, $11,1457$. [CrossRef]

32. Scarano, A.; Inchingolo, F.; Murmura, G.; Traini, T.; Piattelli, A.; Lorusso, F. Three-Dimensional Architecture and Mechanical Properties of Bovine Bone Mixed with Autologous Platelet Liquid, Blood, or Physiological Water: An In Vitro Study. Int. J. Mol. Sci. 2018, 19, 1230. [CrossRef]

33. Piattelli, A.; Artese, L.; Penitente, E.; Iaculli, F.; Degidi, M.; Mangano, C.; Shibli, J.A.; Coelho, P.G.; Perrotti, V.; Iezzi, G. Osteocyte Density in the Peri-Implant Bone of Implants Retrieved after Different Time Periods (4 Weeks to 27 Years). J. Biomed. Mater. Res. Part. B 2014, 102, 239-243. [CrossRef]

34. Gehrke, A.; Mazon, P.; Del Fabbro, M.; Tumedei, M.; Aramburù, J.; Perez-Diaz, L.; De Aza, P. Histological and Histomorphometric Analyses of Two Bovine Bone Blocks Implanted in Rabbit Calvaria. Symmetry 2019, 11, 641. [CrossRef]

35. Kotsu, M.; Urbizo Velez, J.; Bengazi, F.; Tumedei, M.; Fujiwara, S.; Kato, S.; Botticelli, D. Healing at Implants Installed from 70to $<10-$ Ncm Insertion Torques: An Experimental Study in Dogs. Oral Maxillofac. Surg. 2020. [CrossRef]

36. Fujiwara, S.; Kato, S.; Bengazi, F.; Urbizo Velez, J.; Tumedei, M.; Kotsu, M.; Botticelli, D. Healing at Implants Installed in Osteotomies Prepared Either with a Piezoelectric Device or Drills: An Experimental Study in Dogs. Oral Maxillofac. Surg. 2020. [CrossRef]

37. Degidi, M.; Daprile, G.; Piattelli, A. Influence of Stepped Osteotomy on Primary Stability of Implants Inserted in Low-Density Bone Sites: An In Vitro Study. Int. J. Oral Maxillofac. Implants 2017, 32, 37-41. [CrossRef] 
38. Pereira, J.; Morsch, C.S.; Henriques, B.; Nascimento, R.M.; Benfatti, C.A.; Silva, F.S.; López-López, J.; Souza, J.C. Removal Torque and Biofilm Accumulation at Two Dental Implant-Abutment Joints after Fatigue. Int. J. Oral Maxillofac. Implants 2016, 31, 813-819. [CrossRef]

39. Huang, Y.-F.; Liu, S.-P.; Muo, C.-H.; Chang, C.-T. Prosthetic Design Related to Peri-Implant Bone Resorption in Microvascular Free Fibular Flap among Patients with Oral Cancer: A Retrospective Clinical Study. J. Prosthet. Dent. 2020, 124, 395-399. [CrossRef]

40. Madi, M.; Htet, M.; Zakaria, O.; Alagl, A.; Kasugai, S. Re-Osseointegration of Dental Implants after Periimplantitis Treatments: A Systematic Review. Implant Dent. 2018, 27, 101-110. [CrossRef]

41. Dreyer, H.; Grischke, J.; Tiede, C.; Eberhard, J.; Schweitzer, A.; Toikkanen, S.E.; Glöckner, S.; Krause, G.; Stiesch, M. Epidemiology and Risk Factors of Peri-Implantitis: A Systematic Review. J. Periodontal Res. 2018, 53, 657-681. [CrossRef]

42. Albrektsson, T.; Chrcanovic, B.; Östman, P.-O.; Sennerby, L. Initial and Long-Term Crestal Bone Responses to Modern Dental Implants. Periodontol. 2000 2017, 73, 41-50. [CrossRef] [PubMed]

43. Akagawa, Y.; Ichikawa, Y.; Nikai, H.; Tsuru, H. Interface Histology of Unloaded and Early Loaded Partially Stabilized Zirconia Endosseous Implant in Initial Bone Healing. J. Prosthet. Dent. 1993, 69, 599-604. [CrossRef]

44. Araujo, M.G.; Lindhe, J. Peri-Implant Health. J. Periodontol. 2018, 89 (Suppl. 1), S249-S256. [CrossRef] [PubMed]

45. Shibli, J.A.; Melo, L.; Ferrari, D.S.; Figueiredo, L.C.; Faveri, M.; Feres, M. Composition of Supra- and Subgingival Biofilm of Subjects with Healthy and Diseased Implants. Clin. Oral Implants Res. 2008, 19, 975-982. [CrossRef] [PubMed]

46. Misch, C.E. Bone Density: A Key Determinant for Treatment Planning. In Contemporary Implant Dentistry, 3rd ed.; Elsevier: Amsterdam, The Netherlands, 2007; pp. 130-146.

47. Tyrovola, J.B.; Odont, X.X. The "Mechanostat Theory" of Frost and the OPG/RANKL/RANK System. J. Cell. Biochem. 2015, 116, 2724-2729. [CrossRef] [PubMed]

48. Frost, H.M. Bone's Mechanostat: A 2003 Update. Anat. Rec. A 2003, 275, 1081-1101. [CrossRef]

49. Scarano, A.; Noumbissi, S.; Gupta, S.; Inchingolo, F.; Stilla, P.; Lorusso, F. Scanning Electron Microscopy Analysis and Energy Dispersion X-ray Microanalysis to Evaluate the Effects of Decontamination Chemicals and Heat Sterilization on Implant Surgical Drills: Zirconia vs. Steel. Appl. Sci. 2019, 9, 2837. [CrossRef]

50. Maglione, M.; Bevilacqua, L.; Dotto, F.; Costantinides, F.; Lorusso, F.; Scarano, A. Observational Study on the Preparation of the Implant Site with Piezosurgery vs. Drill: Comparison between the Two Methods in Terms of Postoperative Pain, Surgical Times, and Operational Advantages. BioMed Res. Int. 2019, 2019, 8483658. [CrossRef]

51. Degidi, M.; Piattelli, A.; Shibli, J.A.; Perrotti, V.; Iezzi, G. Early Bone Formation around Immediately Restored Implants with and without Occlusal Contact: A Human Histologic and Histomorphometric Evaluation. Case Report. Int. J. Oral Maxillofac. Implants 2009, 24, 734-739.

52. Shibli, J.A.; Mangano, C.; Mangano, F.; Rodrigues, J.A.; Cassoni, A.; Bechara, K.; Ferreia, J.D.B.; Dottore, A.M.; Iezzi, G.; Piattelli, A. Bone-to-Implant Contact around Immediately Loaded Direct Laser Metal-Forming Transitional Implants in Human Posterior Maxilla. J. Periodontol. 2013, 84, 732-737. [CrossRef]

53. Iezzi, G.; Piattelli, A.; Mangano, C.; Shibli, J.A.; Vantaggiato, G.; Frosecchi, M.; Di Chiara, C.; Perrotti, V. Peri-Implant Bone Tissues around Retrieved Human Implants after Time Periods Longer than 5 Years: A Retrospective Histologic and Histomorphometric Evaluation of 8 Cases. Odontology 2014, 102, 116-121. [CrossRef]

54. Lucchese, A.; Carinci, F.; Brunelli, G.; Monguzzi, R. Everstick ${ }^{\circledR}$ and Ribbond ${ }^{\circledR}$ Fiber Reinforced Composites: Scanning Electron Microscope (SEM) Comparative Analysis. Pediatr. Dent. 2011, 3, 17.

55. Rigo, L.; Viscioni, A.; Franco, M.; Lucchese, A.; Zollino, I.; Brunelli, G.; Carinci, F. Overdentures on Implants Placed in Bone Augmented with Fresh Frozen Bone. Minerva Stomatol. 2011, 60, 5-14. [CrossRef] [PubMed]

56. Danza, M.; Zollino, I.; Avantaggiato, A.; Lucchese, A.; Carinci, F. Distance between Implants Has a Potential Impact of Crestal Bone Resorption. Saudi Dent. J. 2011, 23, 129-133. [CrossRef] [PubMed]

57. y Baena, R.R.; Lupi, S.M.; Pastorino, R.; Maiorana, C.; Lucchese, A.; Rizzo, S. Radiographic Evaluation of Regenerated Bone Following Poly(Lactic-Co-Glycolic) Acid/Hydroxyapatite and Deproteinized Bovine Bone Graft in Sinus Lifting. J. Craniofacial Surg. 2013, 24, 845-848. [CrossRef]

58. Amari, Y.; Piattelli, A.; Apaza Alccayhuaman, K.A.; Mesa, N.F.; Ferri, M.; Iezzi, G.; Botticelli, D. Bone Healing at Non-Submerged Implants Installed with Different Insertion Torques: A Split-Mouth Histomorphometric Randomized Controlled Trial. Int. J. Implant Dent. 2019, 5, 39. [CrossRef]

59. Gandini, P.; Schiavi, A.; Manuelli, M.; Camassa, D. Epidemiological Survey of Caries Occurrence in School Age Children. Mondo Ortod. 1989, 14, 63-72.

60. Roncati, M.; Polizzi, E.; Cingano, L.; Gherlone, E.F.; Lucchese, A. Un ausilio all'igiene orale in pazienti diversamente abili. Dent. Cadmos 2013, 81, 447-452. [CrossRef]

61. Prati, C.; Chersoni, S.; Lucchese, A.; Pashley, D.H.; Mongiorgi, R. Dentin Permeability after Toothbrushing with Different Toothpastes. Am. J. Dent. 1999, 12, 190-193.

62. Palmieri, A.; Zollino, I.; Clauser, L.; Lucchese, A.; Girardi, A.; Farinella, F.; Carinci, F. Biological Effect of Resorbable Plates on Normal Osteoblasts and Osteoblasts Derived from Pfeiffer Syndrome. J. Craniofacial Surg. 2011, 22, 860-863. [CrossRef]

63. Matarese, G.; Isola, G.; Ramaglia, L.; Dalessandri, D.; Lucchese, A.; Alibrandi, A.; Fabiano, F.; Cordasco, G. Periodontal Biotype: Characteristic, Prevalence and Dimensions Related to Dental Malocclusion. Minerva Stomatol. 2016, 65, 231-238. [PubMed] 
64. Rodriguez y Baena, R.; Pastorino, R.; Gherlone, E.; Perillo, L.; Saturnino, S.; Lucchese, A. Histomorphometric Evaluation of Two Different Bone Substitutes in Sinus Augmentation Procedures: A Randomized Controlled Trial in Humans. Int. J. Oral Maxillofac. Implants 2017, 32, 188-194. [CrossRef] [PubMed]

65. Manuelli, M. A Peaceful Man. Prog. Orthod. 2012, 13, 1. [CrossRef]

66. Bertossi, D.; Giampaoli, G.; Lucchese, A.; Manuelli, M.; Albanese, M.; Nocini, R.; Nocini, P.F. The Skin Rejuvenation Associated Treatment-Fraxel Laser, Microbotox, and Low G Prime Hyaluronic Acid: Preliminary Results. Lasers Med. Sci. 2019, 34 , 1449-1455. [CrossRef] 